\title{
ASO Author Reflections: Fong's Score in the Era of Modern Strategies for Metastatic Colorectal Cancer
}

\author{
Anthony Turpin, $\mathrm{MD}^{1,2}$, and Mohamed Hebbar, $\mathrm{MD}, \mathrm{PhD}^{1,2}$ \\ ${ }^{1}$ Department of Medical Oncology, Lille University Hospital, Lille, France; ${ }^{2}$ University of Lille, Lille, France
}

\section{PAST}

Several clinicopathologic prognostic factors after liver surgery for metastatic colorectal cancer have been reported whose validity in the era of more effective perioperative chemotherapy remains to be defined). ${ }^{1}$ Particularly Fong's clinical risk score (CRS), the well-known and most validated prognostic model, was established from a population of operated patients during the $1980 \mathrm{~s}$ who received only fluorouracil (5-FU) or no chemotherapy. ${ }^{4}$ The five parameters of Fong's CRS were primary tumor stage N1 or N2, disease-free interval $<12$ months, number of metastases $>1$, preoperative CEA level $>200 \mathrm{ng} / \mathrm{mL}$, and metastasis maximal diameter $>5 \mathrm{~cm}^{2}$

\section{PRESENT}

Our study was designed to analyze the prognostic factors associated with survival in patients who underwent resection for colorectal liver metastases in MIROX phase $3 .^{3,4}$ Based on the findings, Fong's clinical risk score and polymorphonuclear neutrophil count before chemotherapy were independently associated with poor overall survival after resection for colorectal liver metastases. Fong's score also was associated with disease-free survival. Using our

ASO Author Reflections is a brief invited commentary on the article, "Fong's score in the era of modern perioperative chemotherapy for metastatic colorectal cancer: A post hoc analysis of the GERCORMIROX phase III trial," Ann Surg Oncol. 2019. https://doi.org/10. 1245/s10434-019-07976-7.

(C) Society of Surgical Oncology 2019

First Received: 16 October 2019; Published Online: 12 November 2019

A. Turpin, MD

e-mail: anthony.turpin@chru-lille.fr findings, we have established a nomogram that could help surgeons and medical oncologists predict overall survival more accurately before treatment for colorectal liver metastases. We believe our research is of particular interest and use to multidisciplinary teams in liver surgery for colorectal cancer.

\section{FUTURE}

This study revealed that Fong's CRS could still be a relevant prognostic factor in this era of more homogeneous perioperative FOLFOX-based chemotherapy. ${ }^{3}$ It could be useful in daily practice and future trials to select patient more accurately.

DISCLOSURES The authors report no conflicts of interest.

\section{REFERENCES}

1. Spelt L, Andersson B, Nilsson J, et al. Prognostic models for outcome following liver resection for colorectal cancer metastases: a systematic review. Eur J Surg Oncol EJSO. 2012;38(1):16-24.

2. Fong Y, Fortner J, Sun RL, et al. Clinical score for predicting recurrence after hepatic resection for metastatic colorectal cancer. Ann Surg. 1999;230(3):309.

3. Makhloufi S, Turpin A, el Amrani M, et al. Fong's score in the era of modern perioperative chemotherapy for metastatic colorectal cancer: a post hoc analysis of the GERCOR-MIROX phase III trial. Ann Surg Oncol. 2019. https://doi.org/10.1245/s10434-01907976-7.

4. Hebbar M, Chibaudel B, André T, et al. FOLFOX4 versus sequential dose-dense FOLFOX7 followed by FOLFIRI in patients with resectable metastatic colorectal cancer (MIROX): a pragmatic approach to chemotherapy timing with perioperative or postoperative chemotherapy from an open-label, randomized phase III trial. Ann Oncol Off J Eur Soc Med Oncol. 2015;26(2):340-7.

Publisher's Note Springer Nature remains neutral with regard to jurisdictional claims in published maps and institutional affiliations. 